\title{
A Novel Device to assess Hip Strength: Concurrent Validity and Normative values in male athletes
}

Mr Michael O’Brien, Dr Matthew Bourne, Mr Josh Heerey, Dr Ryan Timmins, Dr Tania Pizzari

Mr Michael O’Brien ${ }^{1,2}$, BHSc (Physiotherapy). Email: M.O'Brien2@1atrobe.edu.au

Mr Matthew Bourne ${ }^{1,3}, \mathrm{PhD}$, BAppSci(Hons). Email: $\underline{\text { M.bourne@ griffith.edu.au }}$

Mr Joshua Heerey ${ }^{1}$, B.physio, Grad cert sports physio. Email: J.Heerey@latrobe.edu.au

Dr Ryan Timmins ${ }^{4}$, PhD ASpS2 ESSAM. Email: Ryan.Timmins@acu.edu.au

Dr Tania Pizzari ${ }^{1}$, PhD, B Physio (Hons). (Corresponding author) Email:

T.Pizzari@latrobe.edu.au

${ }^{1}$ La Trobe Sport and Exercise Medicine Research Centre, Bundoora, Victoria, Australia, 3086.

${ }^{2}$ LifeCare Malvern Sports Medicine Centre, 91 Wattletree Rd, Armadale, Victoria, Australia, 3143

${ }^{3}$ Griffith University, School of Allied Health Sciences, Gold Coast, Australia, 4215

${ }^{4}$ Australian Catholic University, Fitzroy, Victoria, Australia 3065 
$\underline{\text { Introduction }}$

Hip and groin problems are common in athletes, can impact on player ability, and may result in persistent pain and motor deficits (1-3). The assessment of hip adductor strength (both as an isolated measure and relative to abductor strength) is advocated for the identification of at-risk athletes $(4,5)$ and for early detection of groin problems $(6,7)$. Two recent systematic reviews identified that athletes who possessed low hip adduction strength (as an isolated measure as well as relative to abduction strength) were more likely to suffer from hip and groin pain, with reports of four times greater risk $(3,8)$. A recent study has also demonstrated that male soccer athletes who have had past-season groin pain for more than 6 weeks are likely to commence the next season with an increased risk of groin injury, due to lower hip adduction squeeze test strength (9). This highlights the need for early diagnosis and comprehensive rehabilitation.

In-season monitoring of hip muscle strength can detect early groin problems in the both elite Australian Rules Football (AFL) (6) and elite football (soccer) (10) and can be used to evaluate recovery following match-play (10). Early detection of strength reductions allows prompt clinical evaluation and commencement of appropriate intervention as required (11). As part of a clinical reasoning process, improving strength scores may help indicate when an athlete is ready for increased resistance in exercises, progression of exercise type or complexity, and ultimately capable of higher workloads. 
Of the methods available for the assessment of hip strength, the most cost-effective and commonly used method is a sphygmomanometer (12). It has been shown to be both valid and reliable for hip adduction strength testing (13), but is susceptible to ceiling effects when testing stronger individuals (12) and is limited to measurement of hip adductor strength only. More recently, hand-held dynamometry (HHD) has been identified as a reliable method for assessing hip strength (14) and provides important information about potential groin problems and injury risk (7, 9-11). However, HHD is susceptible to between-tester bias, with the strength and experience of the assessor influencing testing scores $(14,15)$. Isokinetic dynamometry overcomes this limitation by removing the influence of assessor strength, but is costly, time-consuming, and requires considerable expertise to operate, which may preclude its use in a practical field-based setting. Recently, a novel field-testing device (The GroinBar, VALD Performance, Australia) has been developed to assess hip strength of both limbs simultaneously. It comprises an adjustable rig fitted with four independent and adjustable custom-made uniaxial load cells. Like isokinetic dynamometry, the impact of examiner strength is eliminated, however, the device is portable and does not require extensive training or expertise for use. The device has been shown to have excellent test re-test reliability for adductor strength testing $(I C C=0.94)(16)$, although normative values in elite athletes are yet to be established, and it is not known if strength scores are related to scores measured with the commonly used HHD.

The primary aim of this study was to assess concurrent validity of the new, novel externally-fixed dynamometer (GroinBar) with HHD. The second aim was to provide normative GroinBar scores for elite AFL and football (soccer) players. Our final aim 
was to evaluate preliminary predictive validity of the GroinBar and HHD in this population by comparing strength results with patient reported outcome scores and groin pain history. Our hypotheses was that the GroinBar and HHD would be moderately correlated, and that we would find an association between strength measurements and injury history or self-reported outcomes.

\section{Methods:}

This study was conducted from June to July 2017. Players from two AFL clubs and one A-League football club (senior and youth team) were invited to participate. All participants were male. Players were eligible to participate if they were present and available at the club at the time of testing. Those who were unable to participate in full training because of an injury, sickness or any physical complaint were excluded. Height, weight and leg length were measured by a single investigator (MO) and players provided details on their age, dominant kicking leg, and training and game frequency. All players completed a standardised questionnaire detailing whether they had a history of hip and groin pain in the past six months (and if so, the duration of pain, and number of games missed). In addition, all players completed a physical copy of the Copenhagen Hip \& Groin Outcome Score (HAGOS) (17). Subsequently, players underwent an assessment of their maximal isometric short- and long-lever hip adductor and abductor strength with the GroinBar (VALD Performance, Australia) and HHD in a randomised order. All players provided written, informed consent for their involvement in this study, which was approved by the La Trobe University Human Ethics Committee (HECXX-XXX). 
All participants completed a physical copy of the Copenhagen Hip and Groin Outcome Score (HAGOS). The HAGOS is valid, reliable and responsive in athletes with hip and/or groin pain (17). The HAGOS evaluates hip and groin disability on a scale from 0 to 100 , where 100 represents no hip or groin problems, and 0 represents severe problems. It has six subscales: pain; symptoms; activities of daily living; physical function, sport and recreation; physical activities; and quality of life.

\section{Strength Assessment \\ External Fixed Dynamometry (GroinBar)}

Hip strength of each limb was assessed simultaneously using the GroinBar (VALD Performance, Australia). The device comprises an adjustable rig fitted with four independent and adjustable custom-made uniaxial load cells. Two test positions were evaluated: a short lever and a long lever hip adduction and abduction position.

Short-lever testing was performed in supine with the hips flexed to 45 degrees (Figure 1). For adduction testing, the force transducers were positioned perpendicular to the medial femoral epicondyle and participants performed 3 maximal, 5 second isometric hip adduction efforts separated by a 10 second rest. The highest of the 3 subsequent measurements were used in the analysis. For abduction testing, participants were instructed to perform 3 maximal, 5 second isometric hip abduction efforts with their lateral femoral epicondyle aligned with the force transducer. Long lever testing was completed in supine, with hips and knees at 0 degrees and the force transducers positioned perpendicular to the medial or lateral malleoli (Figure 2). The same number of repetitions and rest parameters were used as for the short lever test. The performance of all efforts was visually monitored and 
a repetition was rejected if the participant displayed excessive hip or knee extension/flexion.

\section{Hand Held Dynamometry}

Hand-held dynamometer data were obtained using the MicroFet2 (Hoggan Health Industries) in only the long lever position. Short lever was not included due to timeconstraints. Long lever was considered preferential to allow for comparison to existing literature which utilises this testing position for adduction to abduction ratio scores (4). Testing position was as described previously by Thorborg et al. (18) with the participants supine on a plinth with the non-testing hip and knee flexed and the ability to stabilise by holding onto the side of the plinth with their hands. To assess abduction, the examiner applied resistance in a fixed position $5 \mathrm{~cm}$ proximal to the proximal edge of the lateral malleolus, and the person being tested exerted a 5second maximum isometric voluntary contraction against the dynamometer. The highest of the 3 subsequent measurements were used in the analysis. There was a 10 second rest period between trials. For adduction testing the same procedure was replicated with resistance applied $5 \mathrm{~cm}$ proximal to the edge of the medial malleolus. All HHD strength tests were conducted by a male physiotherapist (MO), who has experience with HHD testing and working in the elite sport environment.

All GroinBar \& HHD testing was performed immediately prior to a regular training session and the testing sequence order was randomised. Examiners provided standardised verbal encouragement during all trials to ensure maximal effort. 
Data analysis

Force data from The GroinBar were transferred to a personal computer at $50 \mathrm{~Hz}$ through a USB connection using custom made software (Scoreboard, VALD Performance, Australia). The peak force for both limbs (dominant and non-dominant) for each position (short or long lever) was determined automatically through the Scoreboard software and expressed as absolute $(\mathrm{N})$ and relative values $(\mathrm{N} / \mathrm{kg})$. Peak adductor and abductor torque was calculated using weight and limb length for the long lever test position $(\mathrm{Nm} / \mathrm{kg})$ only. The ratio of adduction to abduction strength were also calculated.

Where appropriate, data were screened for normal distribution using the ShapiroWilk test. To examine the strength of the association between HHD and GroinBar scores, a Pearson product-moment correlation coefficient was calculated.

Coefficient results of less than 0.25 were interpreted as showing no relationship; 0.25 to 0.50 was deemed a fair relationship; 0.50 to 0.75 was considered a moderate to good relationship; and 0.75 and above was considered a good to excellent relationship (19). To examine the ability of GroinBar and HHD scores to discriminate players with groin pain history, the cohort was dichotomised into players reporting pain "monthly or never" and those with pain "weekly or more" and an independent sample $t$-test was used to compare group means for GroinBar strength measures in both positions (short and long lever) and HHD measures in long lever position. To further examine the relationship between patient-reported outcomes and strength, the cohort was also dichotomised based on the scores of the physical function, sport and recreation (PFSR) subscale of the HAGOS. As per Delahunt et al. (20), the cohort was dichotomised into PFSR subscale scores $<87.5$, and scores $\geq 87.5$. A 
score below 87.5 on the PFSR subscale has been shown to be associated with groin injury in elite Gaelic football players (20). The PFSR subscale has also been able to distinguish AFL players with and without current groin pain (21). An independent groups $t$-test was used to compare strength between groups (GroinBar and HHD). Due to the multiple comparison, a Bonferroni correction was applied to the alpha level resulting in a $p$-value of $<0.003$. In addition, the correlation between strength scores and all subscale scores of the HAGOS were calculated using a Spearman rank correlation coefficient. All statistical analyses were performed using IBM SPSS Statistics Version 25.

\section{Results}

In total, 67 male athletes including 36 AFL players and 31 football (soccer) players were recruited for this study (age $=20.1 \pm 3.40$, height $=1.84 \mathrm{~m} \pm 0.08$, body mass $=$ $79.2 \mathrm{~kg} \pm 9.19, \mathrm{BMI}=23.4 \pm 1.80)$. (Table 1).

[insert Table one about here]

Moderate to good correlations $(0.53-0.71)$ were identified between the GroinBar and HHD strength tests for hip adduction and abduction in the long lever position (Table 2). Adduction scores showed higher correlations compared with abduction scores, and the ratios displayed only a fair association between the strength testing methods.

[insert Table two about here] 
The normative values of the GroinBar and HHD for both AFL and football (soccer) players are presented in Table 3. Force and torque values are divided into dominant and non-dominant leg for adduction, abduction and adduction:abduction ratio.

[insert Table three about here]

When dichotomised based on frequency of groin pain symptoms, there were no strength differences identified between groups (Table 4). Similarly, when dichotomised based on PFSR subscale scores, no strength differences were identified (Table 4). All correlations between the HAGOS subscale scores and strength tests were weak $\left(r_{s}=0 .-2.6\right.$ to 0.28$)$ (Supplementary file). Average HAGOS subscale scores for all athletes, are presented in Table 6 (Supplementary file).

[insert Table four about here]

\section{Discussion:}

This study identified moderate to good association between the GroinBar device and $\mathrm{HHD}$, which is the current best practice for clinically assessing hip and groin strength $(11,14)$. Preliminary concurrent validity of the GroinBar was demonstrated since findings were equivalent to HHD when evaluating strength results between players with groin problems and those without. Neither strength testing methods identified strength deficits in those with groin problems or lower HAGOS subscale scores. 
The strength of the correlation may have been impacted by the slightly different testing positions and procedures between the two testing methods. The bilateral nature of the GroinBar may evoke a bilateral deficit phenomenon: the inability to generate maximal force when both limbs are operating simultaneously (22-25), which could have impacted on the strength values. During HHD testing, athletes were also able to hold the side of the plinths however this was not reproduced with GroinBar testing, which is performed on the floor. In addition, during abduction testing on the GroinBar the hip is in slight abduction placing the hip abductors slightly in inner range which may also alter force generation and potentially explain the lower correlation values with hip abduction as compared to adduction.

The bilateral nature of the GroinBar testing and the potential for some deficit in maximal voluntary contraction could influence the predictive validity of the test. The test might fail to identify at risk players if the muscle activity does not reflect the maximum output for that player or is variable between testing. However, since both the HHD and GroinBar strength results were not different between players with and without groin problems, this concern may not be warranted. Further testing of the impact of this phenomenon in groin strength testing would be appropriate. The unilateral readings from the GroinBar while performing bilateral movements do make it time-effective, an important factor in a busy sporting or clinic environment.

The advantage of a portable, externally fixed device is clear, particularly for measuring strength in the lower extremity. Between-tester bias has been demonstrated when using the HHD for testers of different strength, with larger tester discrepancy when testing stronger participants (15). Recent evidence demonstrates 
excellent test-retest (19) of the GroinBar in an elite athlete population (16).

Additionally, the GroinBar does not require extensive assessor experience.

This study identified no association between strength measurements and injury history or HAGOS subscale scores. This is consistent with other studies that have looked at the association between patient-reported outcomes and isometric strength (5). Thorborg and colleagues (5) found soccer players with adductor-related groin pain in the dominant leg had no significant difference in isometric hip strength when compared to matched-controls with no pain. However, they did find eccentric hip adduction strength was lower in the adductor-related groin pain group (5). Esteve et al (9) also found no difference between those with and without past-season groin pain for hip adduction strength. However, when dichotomised into those with pastseason groin pain lasting longer than 6 weeks, showed lower values on both shortlever and long-lever squeeze testing. Our study only included one participant who had past-season groin pain exceeding 6 weeks, making this finding unreproducible in our study.

\section{Limitations}

No adverse events or injuries occurred during the testing. There were several limitations to this study that warrant discussion. First, the sample size may not have been large enough to detect small to moderate associations between strength and injury history or HAGOS subscale scores. Also, with numerous maximal efforts needing to be performed, there is some potential for fatigue to affect the latter tests. Randomisation was utilised to reduce this factor, however, it is still a possibility that this affected results. Since all our participants were male athletes, this limits the 
ability to extrapolate the findings to female athletes or sub-elite athletes. Recall bias is also a limitation due to the self-reported nature of history of pain and questions related to pain onset. Additionally, the absence of a standardised clinical examination prevented classifying those with groin problems as recommended by the Doha Agreement (26). This was outside the scope of this paper but would be of clinical relevance as the separate entities may present differently to the various testing procedures.

Clinical Implications

This study identified a moderate to good correlation between the GroinBar and HHD for hip adduction and abduction strength testing. Given its external fixation and ability to quickly obtain unilateral strength results, the GroinBar may be a useful tool in busy sporting and clinic environments. We found no association between HAGOS subscale scores and isometric strength measurement in elite AFL and soccer players.

Conflict of Interest - None 
References:

1. Mosler AB, Weir A, Eirale C, Farooq A, Thorborg K, Whiteley RJ, et al. Epidemiology of time loss groin injuries in a men's professional football league: a 2-year prospective study of 17 clubs and 606 players. Br J Sports Med. 2017.

2. Werner J, Hagglund $M$, Walden $M$, Ekstrand J. UEFA injury study: a prospective study of hip and groin injuries in professional football over seven consecutive seasons. Br J Sports Med. 2009;43(13):1036-40.

3. Whittaker JL, Small C, Maffey L, Emery CA. Risk factors for groin injury in sport: an updated systematic review. Br J Sports Med. 2015;49(12):803-9.

4. Thorborg K, Serner A, Petersen J, Madsen TM, Magnusson P, Holmich P. Hip adduction and abduction strength profiles in elite soccer players: implications for clinical evaluation of hip adductor muscle recovery after injury. Am J Sports Med. 2011;39(1):121-6. 5. Thorborg K, Branci S, Nielsen MP, Tang L, Nielsen MB, Holmich P. Eccentric and Isometric Hip Adduction Strength in Male Soccer Players With and Without AdductorRelated Groin Pain: An Assessor-Blinded Comparison. Orthop J Sports Med. 2014;2(2):2325967114521778.

6. Crow JF, Pearce AJ, Veale JP, VanderWesthuizen D, Coburn PT, Pizzari T. Hip adductor muscle strength is reduced preceding and during the onset of groin pain in elite junior Australian football players. J Sci Med Sport. 2010;13(2):202-4.

7. Wollin M, Thorborg K, Welvaert M, Pizzari T. In-season monitoring of hip and groin strength, health and function in elite youth soccer: Implementing an early detection and management strategy over two consecutive seasons. J Sci Med Sport. 2018.

8. Ryan J, DeBurca N, Mc Creesh K. Risk factors for groin/hip injuries in field-based sports: a systematic review. Br J Sports Med. 2014;48(14):1089-96.

9. Esteve E, Rathleff MS, Vicens-Bordas J, Clausen MB, Holmich P, Sala L, et al. Preseason Adductor Squeeze Strength in 303 Spanish Male Soccer Athletes: A Crosssectional Study. Orthop J Sports Med. 2018;6(1):2325967117747275.

10. Wollin M, Pizzari T, Spagnolo K, Welvaert M, Thorborg K. The effects of football match congestion in an international tournament on hip adductor squeeze strength and pain in elite youth players. J Sports Sci. 2018;36(10):1167-72.

11. Thorborg K, Reiman MP, Weir A, Kemp JL, Serner A, Mosler A, et al. Clinical Examination, Diagnostic Imaging, and Testing of Athletes With Groin Pain: An EvidenceBased Approach to Effective Management. J Orthop Sports Phys Ther. 2018:1-32.

12. Toohey LA, de Noronha M, Taylor C, Thomas J. The validity and reliability of the sphygmomanometer for hip strength assessment in Australian football players. Physiother Theory Pract. 2018;34(2):131-6.

13. Delahunt E, McEntee BL, Kennelly C, Green BS, Coughlan GF. Intrarater reliability of the adductor squeeze test in gaelic games athletes. J Athl Train. 2011;46(3):241-5.

14. Kemp JL, Schache AG, Makdissi M, Sims KJ, Crossley KM. Greater understanding of normal hip physical function may guide clinicians in providing targeted rehabilitation programmes. J Sci Med Sport. 2013;16(4):292-6.

15. Thorborg K, Bandholm T, Schick M, Jensen J, Holmich P. Hip strength assessment using handheld dynamometry is subject to intertester bias when testers are of different sex and strength. Scand J Med Sci Sports. 2013;23(4):487-93. 
16. Ryan S, Kempton T, Pacecca E, Coutts AJ. Measurement Properties of an Adductor Strength Assessment System in Professional Australian Footballers. Int J Sports Physiol Perform. 2018:1-13.

17. Thorborg K, Holmich P, Christensen R, Petersen J, Roos EM. The Copenhagen Hip and Groin Outcome Score (HAGOS): development and validation according to the COSMIN checklist. Br J Sports Med. 2011;45(6):478-91.

18. Thorborg K, Petersen J, Magnusson SP, Holmich P. Clinical assessment of hip strength using a hand-held dynamometer is reliable. Scand J Med Sci Sports. 2010;20(3):493-501.

19. Portney LG, Watkins MP. Foundations of Clinical Research: Applications to Practice. 3 ed. Upper Saddle River, New Jersey Pearson/Prentice Hall: F. A. Davis PT; 2015.

20. Delahunt E, Fitzpatrick $\mathrm{H}$, Blake $\mathrm{C}$. Pre-season adductor squeeze test and HAGOS function sport and recreation subscale scores predict groin injury in Gaelic football players. Phys Ther Sport. 2017;23:1-6.

21. Drew MK, Lovell G, Palsson TS, Chiarelli PE, Osmotherly PG. Australian football players experiencing groin pain exhibit reduced subscale scores of Activities of Daily Living and Sport and Recreation on the HAGOS questionnaire: A case-control study. Phys Ther Sport. 2017;26:7-12.

22. Jakobi JM, Chilibeck PD. Bilateral and unilateral contractions: possible differences in maximal voluntary force. Can J Appl Physiol. 2001;26(1):12-33.

23. Kuruganti $U$, Murphy T, Pardy T. Bilateral deficit phenomenon and the role of antagonist muscle activity during maximal isometric knee extensions in young, athletic men. Eur J Appl Physiol. 2011;111(7):1533-9.

24. Skarabot J, Alfonso RP, Cronin N, Bon J, Strojnik V, Avela J. Corticospinal and transcallosal modulation of unilateral and bilateral contractions of lower limbs. Eur J Appl Physiol. 2016;116(11-12):2197-214.

25. Skarabot J, Cronin N, Strojnik V, Avela J. Bilateral deficit in maximal force production. Eur J Appl Physiol. 2016;116(11-12):2057-84.

26. Weir A, Brukner P, Delahunt E, Ekstrand J, Griffin D, Khan KM, et al. Doha agreement meeting on terminology and definitions in groin pain in athletes. $\mathrm{Br} J$ Sports Med.

2015;49(12):768-74. 


\section{Table 1. Characteristics of Study Participants}

\begin{tabular}{llll}
\hline & AFL players $(\mathrm{N}=36)$ & Football (Soccer) players & Total \\
& Mean $\pm \mathrm{SD}$ & $(\mathrm{N}=31)$ & $(\mathrm{N}=67)$ \\
& & Mean $\pm \mathrm{SD}$ & Mean $\pm \mathrm{SD}$ \\
& & & \\
& $21.97 \pm 3.00$ & $17.93 \pm 2.41$ & $20.1 \pm 3.40$ \\
Age $($ Years $)$ & $1.87 \pm 0.75$ & $1.81 \pm 0.01$ & $1.84 \pm 0.08$ \\
Height $(\mathrm{m})$ & $84.36 \pm 6.92$ & $73.25 \pm 7.94$ & $79.2 \pm 9.19$ \\
Weight $(\mathrm{kg})$ & $24.16 \pm 1.48$ & $22.46 \pm 1.74$ & $23.4 \pm 1.80$ \\
BMI $\left(\mathrm{kg} / \mathrm{m}^{2}\right)$ & 28 & 28 & 56 \\
Right foot DOM $(\mathrm{n})$ & 8 & 3 & 11 \\
Left foot DOM $(\mathrm{n})$ & & & \\
\hline
\end{tabular}

SD: Standard Deviation; BMI Body Mass Index; DOM: Dominant 
Table 2. Correlation between Hand-held dynamometry and GroinBar Strength

\section{Measures}

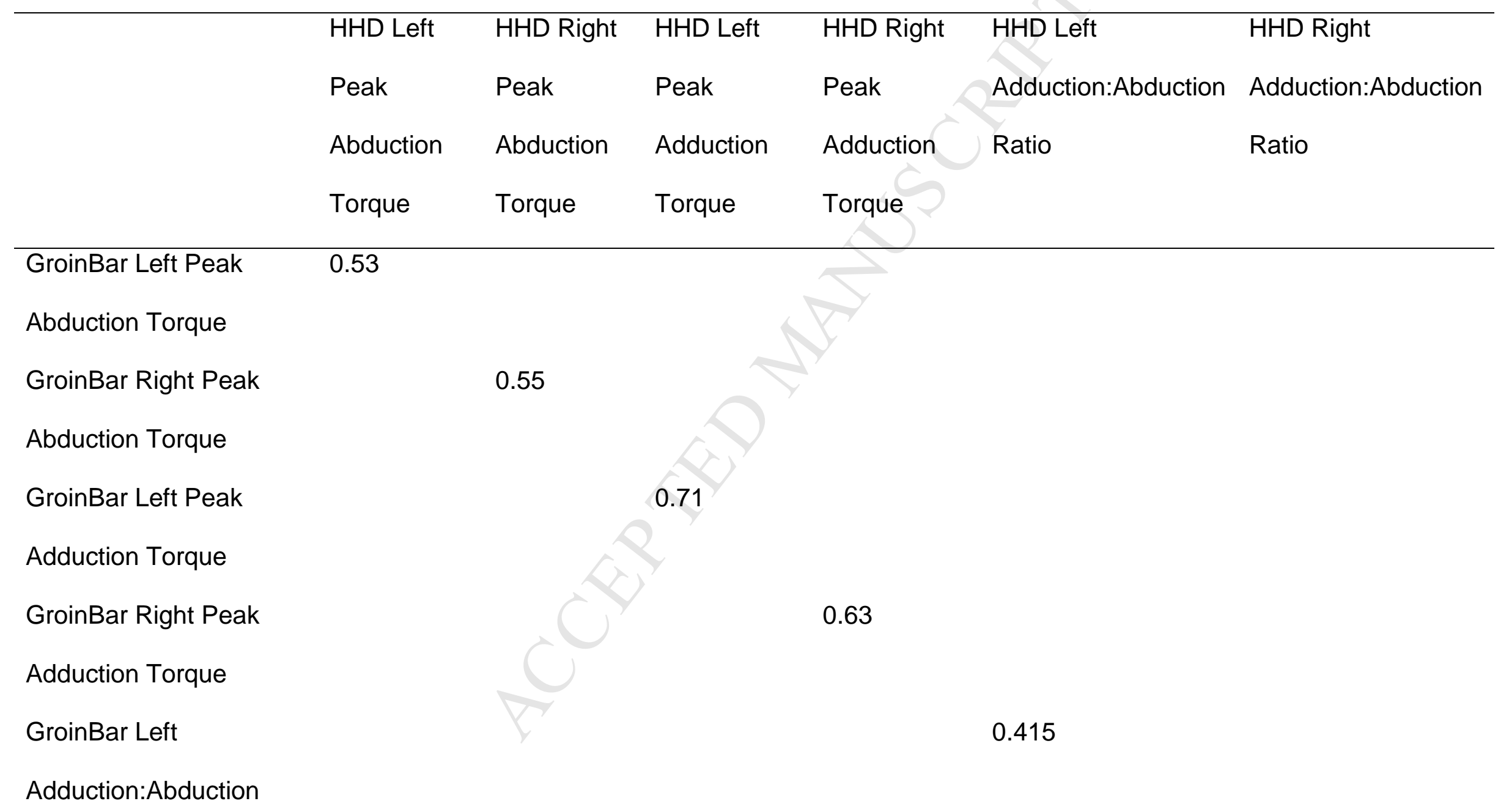


Ratio

GroinBar Left

0.438

Adduction:Abduction

Ratio 
Table 3. Normative Strength Values

\begin{tabular}{|c|c|c|c|c|c|c|c|c|c|c|c|c|c|c|}
\hline & & & \multicolumn{6}{|c|}{ AFL Players } & \multicolumn{6}{|c|}{ Football (Soccer) Players } \\
\hline & & & \multicolumn{3}{|c|}{ Force $(\mathrm{N})$} & \multicolumn{3}{|c|}{ Torque } & \multicolumn{3}{|c|}{ Force $(\mathrm{N})$} & \multicolumn{3}{|c|}{ Torque } \\
\hline & & & Mean & SD & Range & Mean & SD & Range & Mean & SD & Range & Mean & SD & Range \\
\hline Flexed & GB & $\mathrm{D}$ & 387.4 & 82.6 & $227-613$ & 4.6 & 1.0 & $2.2-7.4$ & 385.9 & 78.3 & $215-499$ & 5.4 & 1.2 & $2.8-7.0$ \\
\hline Abduction & & ND & 376.9 & 83.9 & $226-610$ & 4.3 & 1.3 & $2.3-7.4$ & 327.9 & 23.6 & $200-503$ & 5.3 & 1.1 & $2.3-7.0$ \\
\hline Flexed & GB & $\mathrm{D}$ & 346.6 & 107.4 & $169-561$ & 4.1 & 1.2 & $1.6-6.4$ & 361.2 & 109.9 & $187-553$ & 5.1 & 1.7 & $2.3-7.8$ \\
\hline Adduction & & ND & 347.9 & 107.2 & $165-574$ & 4.1 & 1.2 & $1.6-6.6$ & 370.3 & 110.4 & $171-549$ & 5.2 & 1.7 & $2.0-7.6$ \\
\hline Flexed & GB & $\mathrm{D}$ & - & - & - & 0.9 & 0.2 & $0.5-1.5$ & - & - & - & 0.9 & 0.2 & $0.5-1.3$ \\
\hline Adduction: & & ND & - & - & - & 0.9 & 0.3 & $0.5-1.7$ & - & - & - & 1.0 & 0.2 & $0.5-1.6$ \\
\hline Abduction & & & & & & & & & & & & & & \\
\hline Supine & GB & $\mathrm{D}$ & 171.7 & 50.4 & $92-300$ & 2.1 & 0.6 & $0.9-3.3$ & 175.1 & 45.2 & $129-352$ & 2.3 & 0.7 & $1.7-4.8$ \\
\hline Abduction & & ND & 160.2 & 45.9 & $71-270$ & 1.9 & 0.5 & $0.7-2.9$ & 174.6 & 47.1 & $110-342$ & 2.3 & 0.7 & $1.4-4.6$ \\
\hline & $\mathrm{HHD}$ & $\mathrm{D}$ & 202.2 & 32.0 & $144.5-268.2$ & 2.2 & 0.4 & $1.6-2.9$ & 208.5 & 31.4 & $147-267.3$ & 2.5 & 0.4 & $1.6-3.2$ \\
\hline & & ND & 192.7 & 30.2 & $145.9-249.6$ & 2.1 & 0.3 & $1.6-2.7$ & 199.4 & 39.2 & $125.4-296.7$ & 2.4 & 0.5 & $1.2-3.6$ \\
\hline Supine & GB & $\mathrm{D}$ & 199.8 & 32.7 & $145.4-267.8$ & 2.2 & 0.4 & $1.6-3.0$ & 189.8 & 42.2 & $127-258$ & 2.5 & 0.6 & $1.5-3.5$ \\
\hline Adduction & & ND & 192.1 & 41.57 & $97.8-282$ & 2.07 & 0.5 & $1.1-2.8$ & 187.8 & 42.1 & $124-267$ & 2.4 & 0.6 & $1.5-3.6$ \\
\hline
\end{tabular}




\begin{tabular}{|c|c|c|c|c|c|c|c|c|c|c|c|c|c|c|}
\hline & HHD & $\mathrm{D}$ & 179.8 & 46.4 & $70-271$ & 2.1 & 0.6 & $0.7-3.0$ & 204.0 & 33.2 & $138.8-268$ & 2.5 & 0.5 & $1.4-3.3$ \\
\hline & & ND & 181.3 & 52.8 & $81-293$ & 2.1 & 0.6 & $0.8-3.2$ & 203.5 & 40.7 & $134.3-291.4$ & 2.5 & 0.5 & $1.4-3.5$ \\
\hline Supine & GB & $\mathrm{D}$ & - & - & - & 1.1 & 0.2 & $0.8-1.6$ & 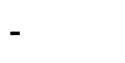 & & - & 1.1 & 0.2 & $0.6-1.5$ \\
\hline Adduction: & & ND & - & - & - & 1.2 & 0.3 & $0.8-2.2$ & & & - & 1.1 & 0.2 & $0.6-1.5$ \\
\hline Abduction & $\mathrm{HHD}$ & $D$ & - & - & - & 1.0 & 0.1 & $0.7-1.3$ & & - & - & 1.0 & 0.2 & $0.7-1.5$ \\
\hline & & ND & - & - & - & 1.0 & 0.2 & $0.5-1.3$ & & - & - & 1.0 & 0.2 & $0.7-1.7$ \\
\hline
\end{tabular}


Table 4 Hip Strength (N.m/kg) with HAGOS PFSR subscale Score above and below $\mathbf{8 7 . 5}$ and Pain Monthly or Never and Weekly or more

\begin{tabular}{|c|c|c|c|c|c|c|c|c|c|}
\hline \multirow[t]{2}{*}{ Strength test } & & \multicolumn{2}{|c|}{ Players with scores PFSR score } & Difference $(95 \% \mathrm{Cl})$ & $\mathrm{P}$ & \multicolumn{2}{|c|}{ Players with pain frequency } & \multirow[t]{2}{*}{ Difference $(95 \% \mathrm{Cl})$} & \multirow[t]{2}{*}{$\mathrm{P}$} \\
\hline & & $>87.5(\mathrm{n}=34)$ & $<87.5(\mathrm{n}=19)$ & & & $\begin{array}{l}\text { monthly or } \\
\text { never ( } \mathrm{N}= \\
42)\end{array}$ & $\begin{array}{l}\text { weekly or } \\
\text { more }(\mathrm{N}=11)\end{array}$ & & \\
\hline \multirow[t]{2}{*}{ GroinBar Flexed Abduction } & Left & $4.84(1.17)$ & $4.80(1.10)$ & $0.04(-0.62,0.70)$ & 0.90 & $4.84(1.14)$ & $4.78(1.19)$ & $0.67(-0.71,0.85)$ & 0.86 \\
\hline & Right & $4.94(1.27)$ & $5.06(1.10)$ & $-0.12(-0.81,0.58)$ & 0.73 & $4.96(1.22)$ & $5.05(1.17)$ & $-0.09(-0.91,0.74)$ & 0.84 \\
\hline \multirow[t]{2}{*}{ GroinBar Flexed Adduction } & Left & $4.73(1.60)$ & $4.43(1.42)$ & $0.30(-0.59,1.18)$ & 0.50 & $4.64(1.55)$ & $4.56(1.54)$ & $0.08(-0.97-1.13)$ & 0.88 \\
\hline & Right & $4.61(1.61)$ & $4.42(1.44)$ & $0.19(-0.70,1.08)$ & 0.67 & $4.55(1.60)$ & $4.52(1.35)$ & $0.02(-1.03,1.08)$ & 0.96 \\
\hline \multirow[t]{2}{*}{ GroinBar Flexed Add:Abd Ratio } & Left & $0.97(0.24)$ & $0.94(0.27)$ & $0.04(-0.11,0.18)$ & 0.60 & $0.96(0.20)$ & $0.97(0.32)$ & $-0.02(-0.19,0.15)$ & 0.83 \\
\hline & Right & $0.93(0.20)$ & $0.88(0.25)$ & $0.44(-0.08,0.17)$ & 0.48 & $0.91(0.20)$ & $0.91(0.27)$ & $-0.00(-0.15,0.15)$ & 0.96 \\
\hline \multirow[t]{2}{*}{ GroinBar Supine Abduction } & Left & $2.01(0.74)$ & $2.03(0.38)$ & $-0.01(-0.39,0.36)$ & 0.94 & $2.00(0.67)$ & $2.09(0.35)$ & $-0.09(-0.54,0.36)$ & 0.69 \\
\hline & Right & $2.11(0.71)$ & $2.24(0.36)$ & $0.13(-0.49,0.23)$ & 0.48 & $2.12(0.65$ & $2.29(0.37)$ & $-0.17(-0.61,0.26)$ & 0.43 \\
\hline \multirow[t]{2}{*}{ GroinBar Supine Adduction } & Left & $2.29(0.69)$ & $2.30(0.47)$ & $0.01(-0.36,0.35)$ & 0.96 & $2.30(0.66)$ & $2.26(0.38)$ & $0.33(-0.39,0.45)$ & 0.88 \\
\hline & Right & $2.26(0.67)$ & $2.26(0.49)$ & $0.01(-0.36,0.34)$ & 0.96 & $2.25(0.65)$ & $2.30(0.43)$ & $-0.05(-0.46,0.36)$ & 0.81 \\
\hline \multirow[t]{2}{*}{ GroinBar Supine Add:Abd Ratio } & Left & $1.19(0.30)$ & $1.16(0.13)$ & $0.28(-0.12,0.18)$ & 0.71 & $1.19(0.27)$ & $1.12(0.14)$ & $0.06(-0.12,0.24)$ & 0.48 \\
\hline & Right & $1.09(0.24)$ & $1.01(0.14)$ & $0.74(-0.35,0.18)$ & 0.18 & $1.07(0.22)$ & $1.02(0.15)$ & $0.52(-0.11,0.21)$ & 0.51 \\
\hline \multirow[t]{2}{*}{ HHD Supine Abduction } & Left & $2.23(0.44)$ & $2.17(0.44)$ & $0.06(-1.92,0.32)$ & 0.62 & $2.21(0.43)$ & $2.22(0.48)$ & $-0.01(-0.31,0.29)$ & 0.94 \\
\hline & Right & $2.38(0.43)$ & $2.38(0.40)$ & $0.02(-0.24,0.24)$ & 0.99 & $2.39(0.41)$ & $2.34(0.45)$ & $0.04(-0.24,0.39)$ & 0.76 \\
\hline \multirow[t]{2}{*}{ HHD Supine Adduction } & Left & $2.32(0.58)$ & $2.21(0.39)$ & $0.11(-0.19,0.41)$ & 0.48 & $2.29(0.54)$ & $2.26(0.45)$ & $0.03(-0.32,0.39)$ & 0.86 \\
\hline & Right & $2.36(0.50)$ & $2.27(0.39)$ & $0.08(-0.26,0.37)$ & 0.57 & $2.32(0.50)$ & $2.35(0.40)$ & $-0.03(0.17,-0.37)$ & 0.85 \\
\hline
\end{tabular}




\begin{tabular}{|c|c|c|c|c|c|c|c|c|c|}
\hline \multirow[t]{2}{*}{ HHD Supine Add:Abd Ratio } & Left & $1.05(0.20)$ & $1.03(0.13)$ & $0.16(-0.09,0.12)$ & 0.76 & $1.05(0.19)$ & $1.03(0.14)$ & $0.17(-0.10,0.14)$ & 0.78 \\
\hline & Right & $0.98(0.18)$ & $0.96(0.14)$ & $0.02(0.07,0.12)$ & 0.61 & $0.97(0.18)$ & $1.00(0.96)$ & $-0.04(-0.15,0.77)$ & 0.52 \\
\hline
\end{tabular}




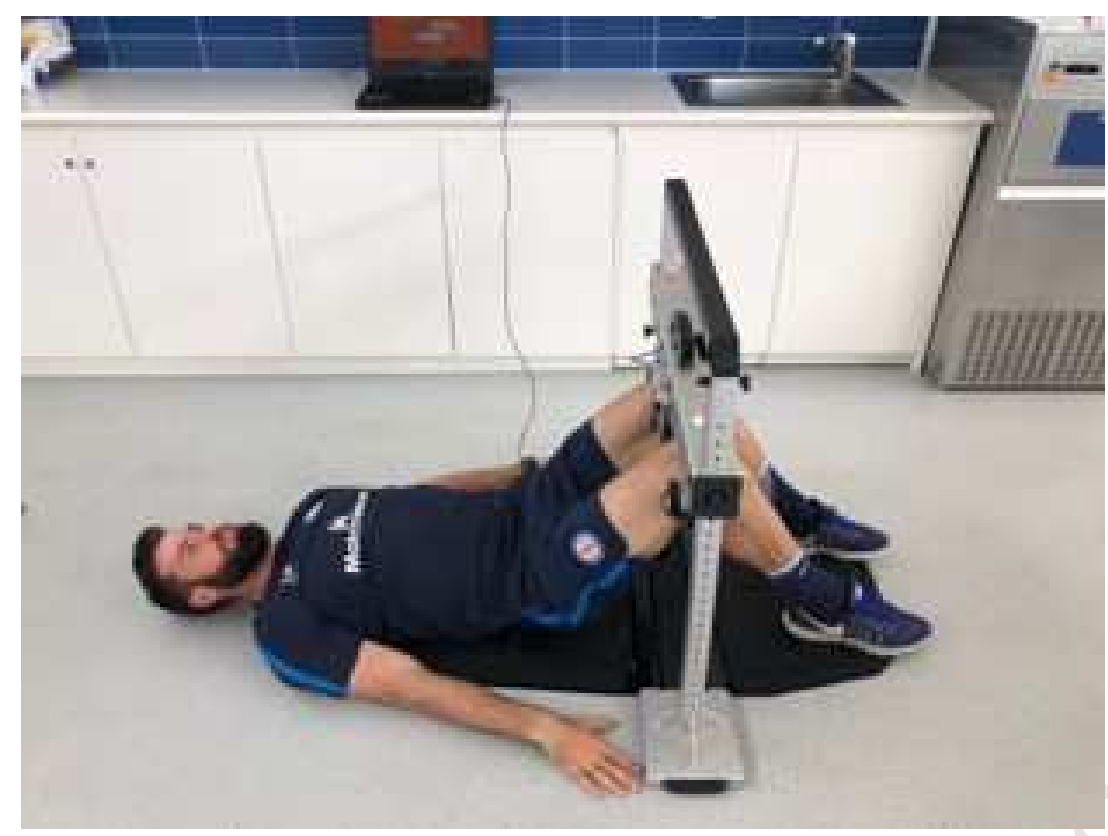




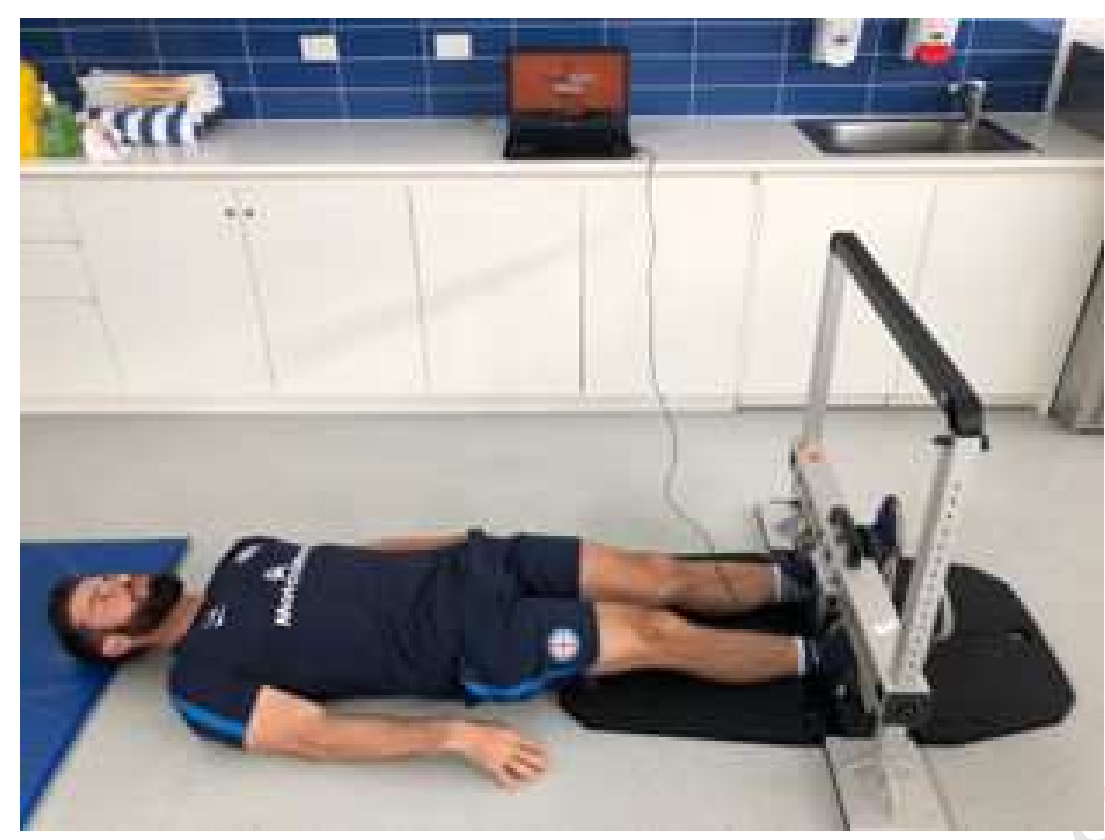


$\underline{\text { Highlights }}$

- New novel device (GroinBar) correlates well with hand-held dynamometry for hip strength testing

- Normative values for male Australian rules football and football (Soccer) players identified

- No differences in strength found between those with and without past history of groin pain 


\section{Conflict of Interest}

Conflict of Interest: N/A

Ethical Statements: This project was approved by the La Trobe University Human Ethics Committee (HEC 16-118)

Funding: N/A

Acknowledgements: N/A 


\section{Accepted Manuscript}

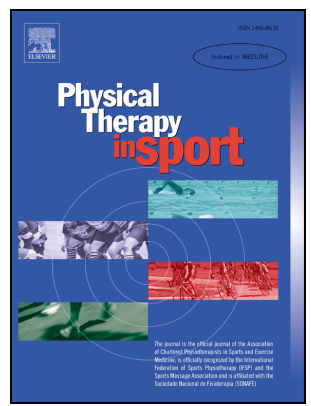

A novel device to assess hip strength: Concurrent validity and normative values in male athletes

Mr Michael O'Brien, Mr Matthew Bourne, Mr Joshua Heerey, Dr Ryan Timmins, Dr Tania Pizzari

PII: S1466-853X(18)30400-0

DOI: https://doi.org/10.1016/j.ptsp.2018.11.006

Reference: $\quad$ YPTSP 977

To appear in: Physical Therapy in Sport

Received Date: 21 August 2018

Revised Date: 9 November 2018

Accepted Date: 10 November 2018

Please cite this article as: O'Brien, M.M., Bourne, M.M., Heerey, M.J., Timmins, D.R., Pizzari, D.T., A novel device to assess hip strength: Concurrent validity and normative values in male athletes, Physical Therapy in Sports (2018), doi: https://doi.org/10.1016/j.ptsp.2018.11.006.

This is a PDF file of an unedited manuscript that has been accepted for publication. As a service to our customers we are providing this early version of the manuscript. The manuscript will undergo copyediting, typesetting, and review of the resulting proof before it is published in its final form. Please note that during the production process errors may be discovered which could affect the content, and all legal disclaimers that apply to the journal pertain. 